\title{
The Hypersensitive Response to Tomato leaf curl New Delhi virus Nuclear Shuttle Protein Is Inhibited by Transcriptional Activator Protein
}

\author{
Mazhar Hussain, Shahid Mansoor, Shazia Iram, Yusuf Zafar, and Rob W. Briddon \\ National Institute for Biotechnology and Genetic Engineering, Jhang Road, Faisalabad, Pakistan
}

Submitted 22 February 2007. Accepted 11 July 2007.

\begin{abstract}
The hypersensitive response $(\mathrm{HR})$ is a common feature of plant disease resistance reactions and a type of programmed cell death (PCD). Many pathogens are able to modulate pathways involved in cell death. In contrast to animal viruses, inhibitors of PCD activity have not been identified for plant-infecting viruses. Previously, we have reported that the nuclear shuttle protein (NSP) of Tomato leaf curl New Delhi virus (ToLCNDV) induces an HR in Nicotiana tabacum and Lycopersicon esculentum plants when expressed under the control of the Cauliflower mosaic virus 35S promoter. However, HR is not evident in plants infected with ToLCNDV, suggesting that the virus encodes a factor (or factors) that counters this response. Analysis of all ToLCNDV-encoded genes pinpointed the transcriptional activator protein (TrAP) as the factor mediating the anti-HR effect. Deletion mutagenesis showed the central region of $\mathrm{TrAP}$, containing a zinc finger domain and nuclear localization signal, to be important in inhibiting the HR. These results demonstrate that TrAP counters HR-induced cell death, the first such activity identified for a plant-infecting virus.
\end{abstract}

In plant-pathogen interactions, the hypersensitive response (HR) is an active defense response, resulting from activation of defense-related pathways which lead to rapid cell death (Baker et al. 1997; Hammond-Kosack and Jones 1996; Heath 2000). The HR is a form of programmed cell death (PCD), with the affected cells being metabolically active (Nozue et al. 1997). It often is associated with a transient burst of reactive oxygen intermediates, fortification of cell walls, accumulation of antimicrobial phytoalexins, and activation of pathogenesisrelated genes (Dangl et al. 1996; Hammond-Kosack and Jones 1996). This type of cell death is genetically controlled and several proteins have been identified which play vital roles in repressing or enhancing HR in plants (Greenberg and Yao 2004; Hoeberichts and Woltering 2002; Loake 2001).

The cell death resulting from an HR is believed to assist in resistance by containing the pathogen although, in some cases, $\mathrm{HR}$ and resistance are uncoupled (Balague et al. 2003; Clough et al. 2000; Garrido-Ramirez et al., 2000; Jurkowski et al. 2004; Yu et al. 1998). In order to promote their virulence, pathogens have evolved the ability to target and suppress PCD.

Corresponding author: S. Mansoor; Telephone: +92 41 2651475; Fax: +92 41 2651472; E-mail: smansoor@ nibge.org

* The $\boldsymbol{e}$-Xtra logo stands for "electronic extra" and indicates that Figures 1 and 2 appear in color online.
For numerous animal viruses, escape from the PCD defense response is mediated by specific, virus-encoded, antiapoptotic proteins (Hay and Kannourakis 2002). Similarly, many plantinfecting pathogens, including bacteria, fungi, and nematodes, have been shown to modulate (both induce and repress) PCD in hosts. For phytopathogenic viruses, although there is ample evidence that they have the ability to overcome host PCD, only host factors triggering hypersensitive cell death have been identified (Greenberg and Yao 2004).

Geminiviruses are phytopathogenic, single-stranded (ss)DNA viruses which replicate in the nucleus through a doublestranded, replicative intermediate (Hanley-Bowdoin et al. 2004). Viruses of the Geminiviridae genus Begomovirus, encompassing the majority of the dicot-infecting and economically important geminiviruses, usually have genomes consisting of two ssDNA circles (known as DNA A and DNA B), each approximately 2,800 nucleotides in length (Stanley et al. 2005). Monopartite begomoviruses lack the DNA B component which encodes two products, the movement protein (MP) and the nuclear shuttle protein (NSP), that are involved in interand intracellular movement, respectively (Rojas et al. 2005; Sanderfoot and Lazarowitz 1996). The DNA A component encodes gene products involved in replication (the replicationassociated protein [Rep; a rolling circle replication initiator protein] and the replication enhancer protein [REn]), activating late gene expression (transcriptional activator protein [TrAP]), insect transmission (coat protein [CP]), and two genes whose precise functions remain unclear but that are implicated in pathogenicity (AC4) and viral movement (AV2). Whether a fifth complementary-sense open reading frame (AC5), which is conserved between distinct begomoviruses, is translated remains unclear. A possible function for this gene product in viral DNA replication has been shown experimentally (Raghavan et al. 2004). In addition to acting as a transcription factor for expression of late genes, for a number of begomoviruses, TrAP also has been demonstrated to suppress host defense mediated by post-transcriptional gene silencing (PTGS) (Trinks et al. 2005; Vanitharani et al. 2003; van Wezel et al. 2002b; Wang et al. 2005).

Several geminivirus-encoded gene products are avirulence factors that induce an HR in some hosts, including the NSP of Bean dwarf mosaic virus and Tomato leaf curl New Delhi virus (ToLCNDV) (Garrido-Ramirez et al. 2000; Hussain et al. 2005). However, natural infection by ToLCNDV does not induce an HR. This incongruity was the first evidence suggesting that begomoviruses may encode factors to overcome PCD. To identify the potential virus-encoded factor or factors involved in mediating avoidance by geminiviruses of the host's HR, we have examined the ability of each ToLCNDV-encoded gene to 
inhibit cell death induced in tomato and tobacco by NSP. This work demonstrated that only one gene product, TrAP, was capable of inhibiting the HR. In addition, sequences of TrAP important in mediating the anti-HR effect were mapped by deletion mutagenesis.

\section{RESULTS}

\section{ToLCNDV inhibits HR-induced cell death.}

We have shown previously that the NSP of ToLCNDV is an avirulence determinant which induces an HR in tomato and tobacco when expressed from a Potato virus $X$ (PVX) vector (Hussain et al. 2005). No such response is seen when ToLCNDV infects these hosts, suggesting that the virus has some mechanism to avoid eliciting this response. To confirm this hypothesis, leaves of tomato or tobacco plants were coinfiltrated with Agrobacterium cultures harboring a construct for the transient expression of ToLCNDV NSP under the control of the Cauliflower mosaic virus 35S promoter (NSP/35S) and various virus constructs. Infectious (when Agrobacterium cultures harboring both DNA A and DNA B are coinoculated to susceptible plants) (Hussain et al. 2003), partial repeat constructs of either ToLCNDV component DNA A or component DNA B were used. When inoculated in isolation or in the presence of ToLCNDV DNA B, NSP/35S infiltrated tomato leaves developed a severe $\mathrm{HR}$ at the site of inoculation, covering the inoculated patch. No HR was evident in leaves coinoculated with NSP/35S and ToLCNDV DNA A (Fig. 1). These results suggest that some factor (or factors) encoded on DNA A is able to inhibit the HR of tomato and tobacco to ToLCNDV NSP expression. In addition, tobacco plants systemically infected with the cloned components of ToLCNDV infiltrated with NSP/35S showed a marked reduction in the level of HR

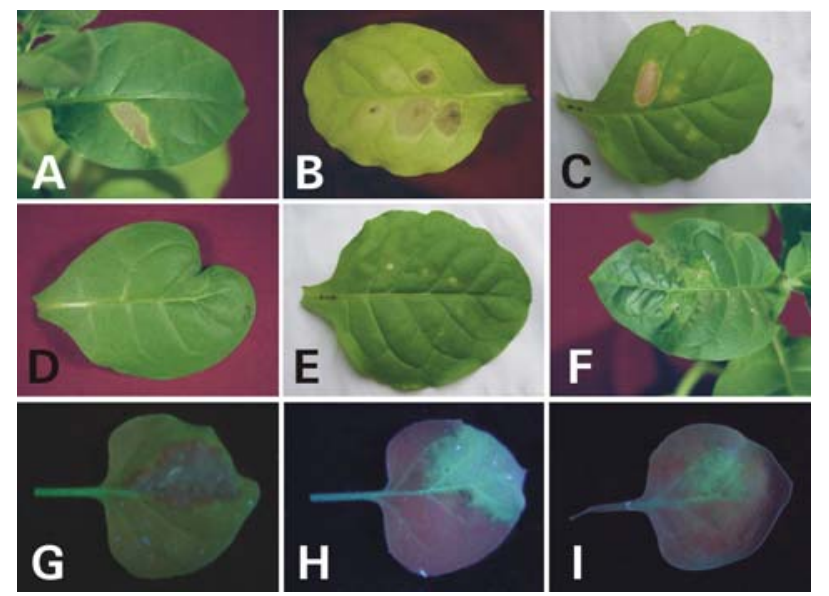

Fig. 1. Inhibition of hypersensitive response (HR) by the components of distinct begomoviruses. A, HR induced by inoculation with an Agrobacterium culture harboring a construct expressing the nuclear shuttle protein (NSP). Leaves of tobacco plants were co-infiltrated with Agrobacterium cultures harboring constructs for the expression of Tomato leaf curl New Delhi virus (ToLCNDV) NSP and partial repeat constructs of the genomes (or DNA A components) of B, Cotton leaf curl Multan virus, C, African cassava mosaic virus DNA A, D, ToLCNDV DNA A and $\mathbf{E}$, Indian cassava mosaic virus DNA A. F, A systemic ToLCNDV infection of tobacco has the ability to inhibit HR induced by transient expression of NSP. The ability of ToLCNDV transcriptional activator protein (TrAP) to suppress post-transcriptional gene silencing is shown in leaves of $N$. benthamiana 16c plants G, inoculated with an Agrobacterium culture harboring a green fluorescent protein (GFP) RNAi construct and co-inoculated with an Agrobacterium culture harboring a GFP RNAi construct and Agrobacterium cultures containing constructs for expression of either $\mathbf{H}$, Tomato bushy stunt virus $\mathrm{p} 19$ or I, ToLCNDV TrAP. Photos were taken 5 days postinoculation.
(Fig. 1F) compared with noninfected plants inoculated with this construct (Fig. 1A).

\section{ToLCNDV TrAP Inhibits NSP-induced cell death.}

To determine which ToLCNDV DNA A-encoded product is responsible for overcoming the HR, constructs for the expression of each DNA A-encoded gene under the control of the $35 \mathrm{~S}$ promoter were produced. When expressed in isolation, following Agrobacterium infiltration to tomato or tobacco leaves, Rep was found to induce an HR (results not shown). This type of response to Rep expression in plants has been shown for a number of other begomoviruses (Selth et al. 2004; van Wezel et al. 2002a). For the remaining genes, transient expression in tomato leaves was found to have no discernable effect (results not shown). Coexpression of the remaining DNA A-encoded genes (REn, AC4, AC5, AV2, and CP), with the exception of TrAP, in the presence of NSP had no effect on induction of HR (Fig. 2). Similarly, 35S promoter-driven expression of the DNA B-encoded MP of ToLCNDV was unable to inhibit cell death. However, leaves coinoculated with Agrobacterium cultures harboring TrAP/35S and NSP/35S did not develop HR. These results demonstrate that TrAP is able to counter cell death initiated by the HR to NSP expression.

\section{Mapping TrAP sequences essential \\ for inhibition of cell death.}

To map the TrAP sequences responsible for inhibiting induction of the HR and identify possible functional domains, TrAP coding sequences containing $\mathrm{N}$ - and $\mathrm{C}$-terminal truncations were cloned under the control of the $35 \mathrm{~S}$ promoter (Fig. 3). Constructs were engineered such that translation of the TrAP constructs with C-terminal truncations occurred from the authentic initiation codon, whereas in-frame initiation codons were introduced into the $\mathrm{N}$-terminal truncations. Coinoculation of Agrobacterium cultures harboring constructs for the expression of NSP and TrAP with deletions of C-terminal sequences (constructs TrAP ${ }^{\mathrm{dmC} 20} / 35 \mathrm{~S}$ and $\mathrm{TrAP} \mathrm{P}^{\mathrm{dmC} 40} / 35 \mathrm{~S}$ ) did not elicit an HR. Similarly, TrAP in which the N-terminal 20 amino acids were deleted ( $\left.\mathrm{TrAP}^{\mathrm{dmN} 20} / 35 \mathrm{~S}\right)$ was capable of inhibiting the HR. However, deletion of the N-terminal 60 amino acids of $\operatorname{TrAP}\left(\operatorname{TrAP}{ }^{\mathrm{dmN} 60} / 35 \mathrm{~S}\right)$ completely abolished the ability of this protein to inhibit the NSP-induced HR. For a mutant in which amino acids 60 to 100 were deleted $\left(\operatorname{TrAP} \mathrm{P}^{\mathrm{dm} 60-80} / 35 \mathrm{~S}\right)$, HR was delayed and attenuated. These findings indicate that amino acids between positions 20 and 60 are important for inhibition of the HR response of tomato and tobacco to NSP of ToLCNDV. However, the delayed HR with construct TrAP ${ }^{d m 60-}$ ${ }^{80} / 35 \mathrm{~S}$ suggests that sequences adjacent to the deletion may play a minor, enhancing role in inhibiting HR. In order to further dissect the region between amino acids 20 and 60, two further TrAP deletion constructs were produced. Both of these constructs $\left(\mathrm{TrAP} \mathrm{P}^{\mathrm{dmNLS}} / 35 \mathrm{~S}\right.$ and $\mathrm{TrAP} \mathrm{P}^{\mathrm{dmZF}} / 35 \mathrm{~S}$, with deletions of the nuclear localization signals [NLS] and the zinc finger $[\mathrm{ZF}]$ domains, respectively) failed to inhibit the HR. These findings demonstrate that both NLS and ZF domain sequences are important in inhibition of the HR.

The production and functional integrity of proteins produced by TrAP constructs was assessed using a transactivation assay, utilizing the property of (intact) TrAP to upregulate transcription from the virion-sense promoter. This showed that $\mathrm{N}$-terminal sequences are not essential for transactivation, whereas $\mathrm{C}$ terminal sequences are, confirming the results of previous studies (Sunter and Bisaro 2003) (Fig. 3). These findings indicate that, for the majority of constructs, TrAP is expressed. In addition, failure of a nontranslatable TrAP gene construct $\left(\operatorname{TrAP} \mathrm{P}^{\mathrm{NT}} / 35 \mathrm{~S}\right)$ to inhibit HR confirms the role of protein, rather than nucleic acid sequences, in the inhibition of HR. 

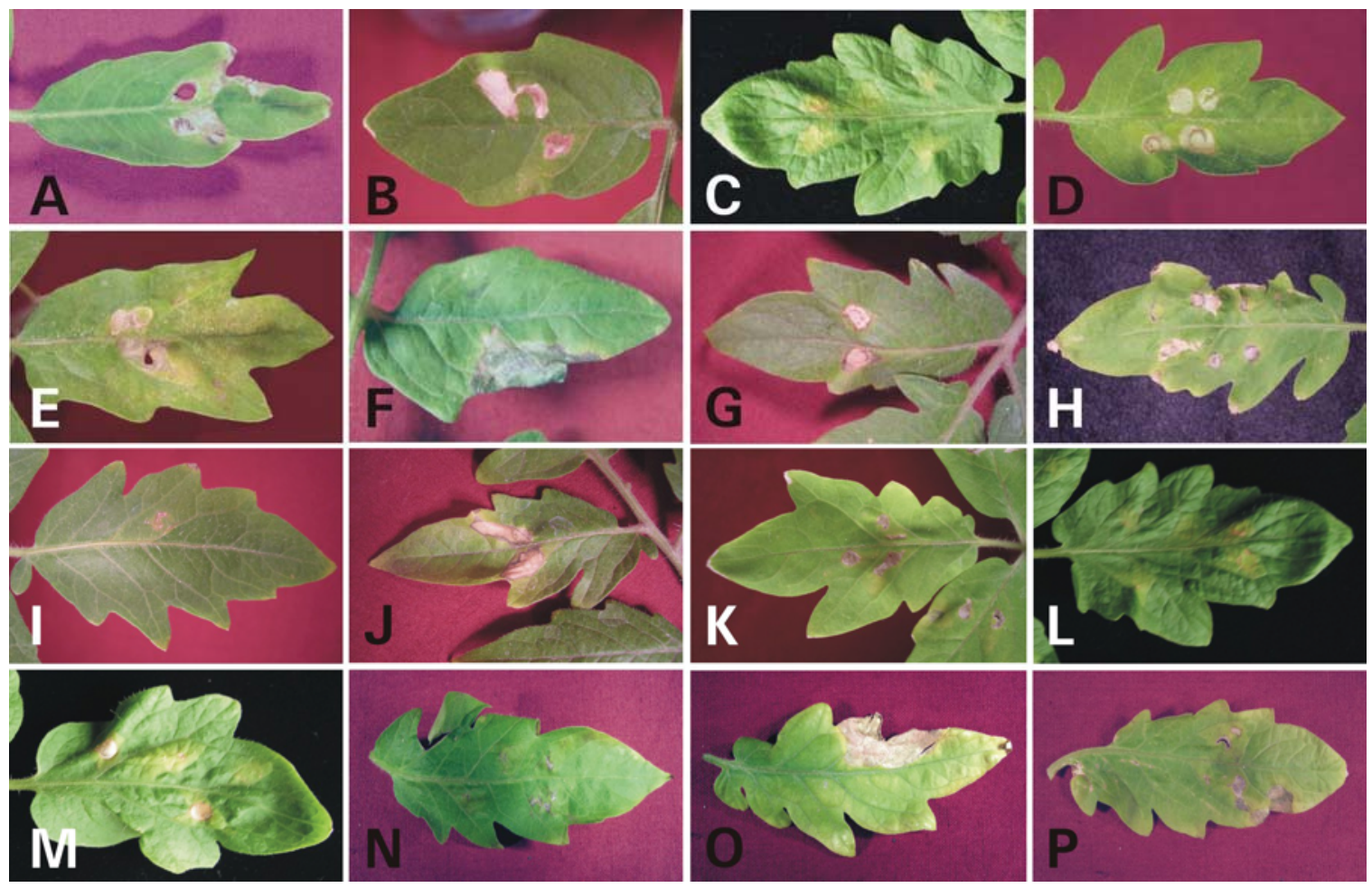

Fig. 2. Inhibition of hypersensitive response (HR) by individual Tomato leaf curl New Delhi virus (ToLCNDV) gene products. Leaves of tomato plants were co-infiltrated with Agrobacterium cultures harboring a construct expressing ToLCNDV nuclear shuttle protein (NSP) under the control of the 35S promoter and constructs for expression of either the A, coat protein, B, AV2, C, transcriptional activator protein (TrAP), D, replication enhancer protein, E, AC4, F, AC5, or G, movement protein full-length genes. H, HR induced by inoculation with an Agrobacterium culture harboring a construct for expression of NSP. The remaining leaves were co-inoculated with Agrobacterium cultures harboring the NSP expression construct and constructs for the expression of the TrAP deletion mutants I, TrAP ${ }^{\mathrm{dmN} 20} / 35 \mathrm{~S}, \mathbf{J}, \operatorname{TrAP}^{\mathrm{dmN60}}, \mathbf{K}, \operatorname{TrAP}^{\mathrm{dm} 60-80}, \mathbf{L}, \operatorname{TrAP}^{\mathrm{dmC20}}, \mathbf{M}, \operatorname{TrAP}^{\mathrm{dmC40}}, \mathbf{N}, \operatorname{TrAP}^{\mathrm{dmNLS}}, \mathbf{O}, \operatorname{TrAP} \mathrm{P}^{\mathrm{dmZF}}$, and $\mathbf{P}, \operatorname{TrAP}^{\mathrm{NT}}$. Photographs were taken approximately 7 days after infiltration.

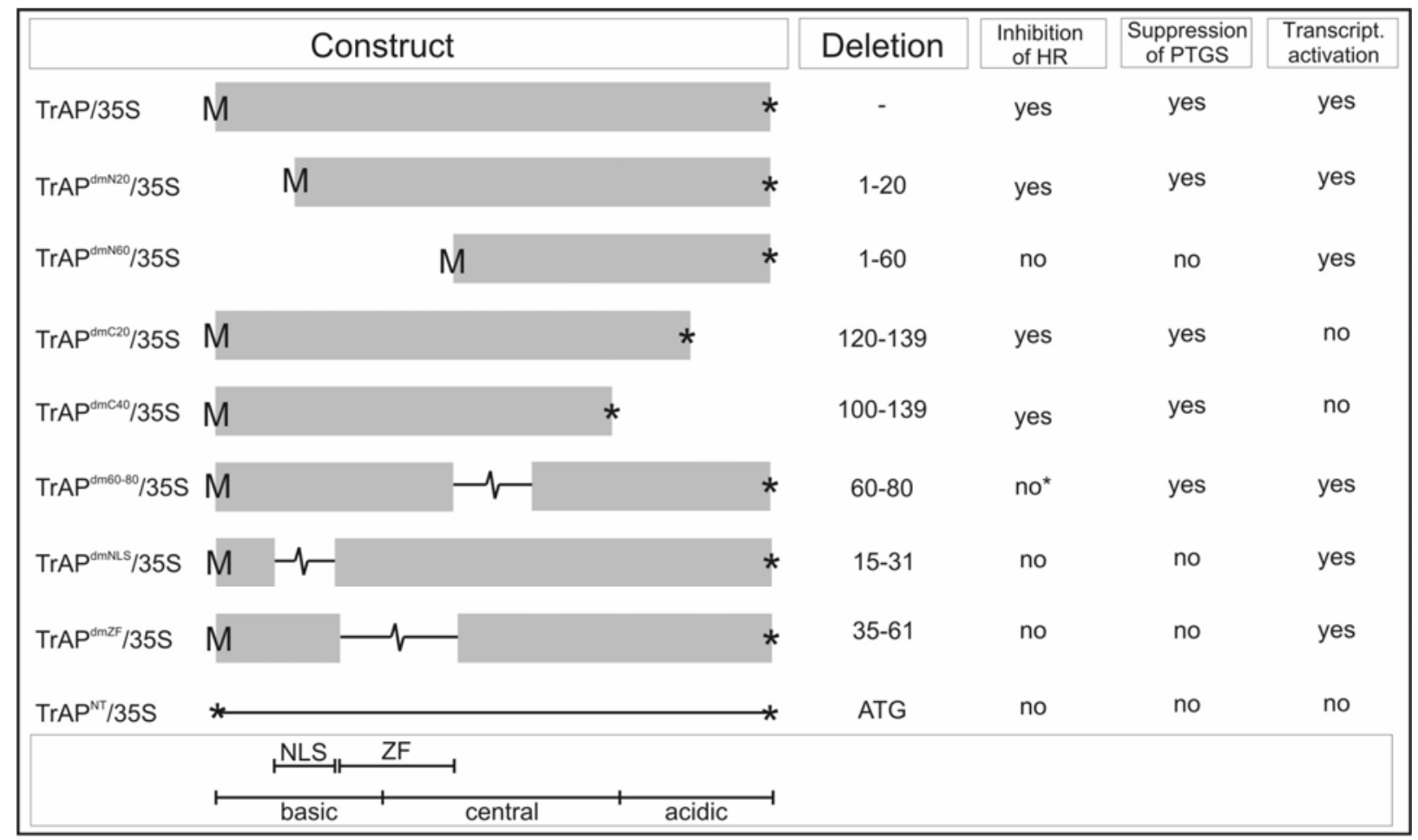

*delayed HR

Fig. 3. Diagrammatic representation of the transcriptional activator protein constructs. The positions of methionine initiation codons (M) and termination (nonsense) codons $(*)$ and the presumed extend of the translated product (shaded bars) are shown. The results of the suppression of hypersensitive response, suppression of post-transcriptional gene silencing (PTGS) assays, and transactivation (of the virion-sense promoter) assays for each construct are shown on the right. The approximate extent of the basic (N-terminal), central, and acidic (C-terminal) domains, as well as of the nuclear localization signal (NLS) and zinc finger domain $(\mathrm{ZF})$, are indicated. 


\section{Inhibition of ToLCNDV NSP induced HR} by heterologous begomoviruses.

To examine whether other begomoviruses similarly encode proteins capable of blocking the HR elicited by ToLCNDV NSP, Agrobacterium cultures harboring NSP/35S were coinfiltrated with the infectious constructs of the genomes (or DNA A components) of three distinct begomoviruses (Fig. 1). Of these, Cotton leaf curl Multan virus (CLCuMV, a monopartite begomovirus originating from Pakistan, which requires a satellite to symptomatically infect some hosts) (Briddon and Stanley 2006) and African cassava mosaic virus (ACMV, a typical bipartite begomovirus originating from Africa) (Klinkenberg et al. 1989) DNA A were unable to inhibit the HR elicited by NSP. However, coinoculation with Indian cassava mosaic virus (ICMV, a bipartite begomovirus originating from India) (Saunders et al. 2002) DNA A completely inhibited the response of tomato to NSP. In each case, nucleic acids were extracted from the infiltrated patch at the end of the experiment and the replication of the virus component was confirmed by Southern hybridization (results not shown). Thus, at least some other begomoviruses encode a product that, like ToLCNDV TrAP, can inhibit HR-induced cell death.

\section{ToLCNDV TrAP is a suppressor of PTGS.}

For several begomoviruses, the TrAP has been shown to be capable of suppressing PTGS. The ability of ToLCNDV TrAP to suppress PTGS was investigated by coinfiltration of Agrobacterium cultures harboring constructs $\operatorname{TrAP} / 35 \mathrm{~S}$ and $\mathrm{GFP}^{\mathrm{RNAi}} / 35 \mathrm{~S}$ (a construct consisting of fragments of the green fluorescent protein [GFP] expressed in sense and anti-sense orientations designed to induce PTGS of GFP, as previously described by Wang and associates [2005]) to leaves of Nicotiana benthamiana line 16c plants. Within 6 days of inoculation, the infiltrated patch of $16 \mathrm{c}$ plants inoculated with only the silencing construct GFP RNAi/35S fluoresced red under UV illumination, indicative of silencing of the GFP transgene (Fig. 1). The patches of 16c plants coinoculated with Agrobacterium cultures harboring the silencing construct and TrAP/35S continued to fluorescence green under UV, demonstrating suppression of silencing by TrAP. The previously produced deletion mutants of TrAP used in this assay system revealed that sequences within the first 100 amino acids are important for suppressor activity and that the NLS and ZF sequences are essential for suppression (Fig. 1).

\section{DISCUSSION}

Many incompatible plant-pathogen interactions activate a host defense mechanism that leads to hypersensitive lesions. These appear as areas of dead cells at the point of pathogen contact. An HR response can be triggered by pathogenic fungi, viruses, bacteria, and nematodes and is associated with expression by the pathogen of an avirulence determinant which is recognized by the corresponding host-encoded resistance gene (Morel and Dangl 1997). Thus, the HR appears to play the same role as PCD (apoptosis) in animals with respect to pathogen containment. The view that PCD is a part of host defense is supported by the fact that animal viruses encode suppressors of PCD. Although several plant-encoded factors which either induce or inhibit PCD have been identified (Greenberg and Yao 2004) and these are able to counter virus induced PCD, thus far no factors encoded by phytopathogenic viruses capable of abrogating PCD have been identified. However, by analogy, phytopathogenic viruses must be able to prevent or avoid containment by the HR in order to spread effectively in hosts.

We have shown previously that the NSP of ToLCNDV is an avirulence determinant, inducing an HR in tomato and tobacco plants (Hussain et al. 2005). However, systemic infection of

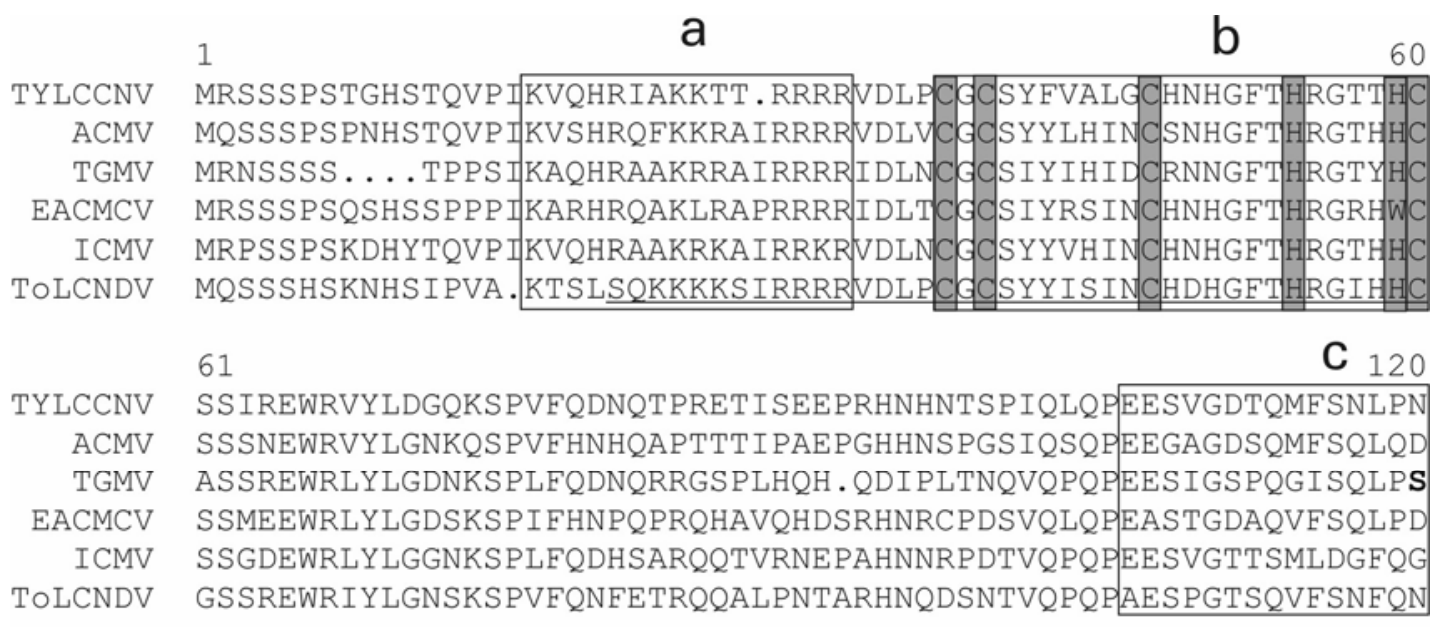

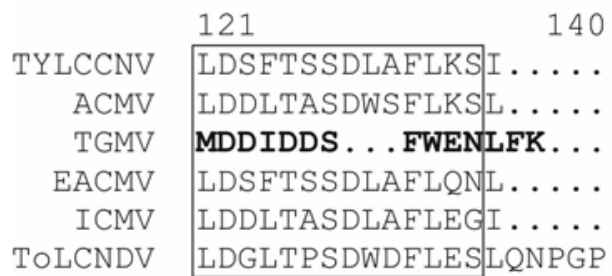

Fig. 4. Alignment of the predicted amino acid sequence of Tomato leaf curl New Delhi virus (ToLCNDV) transcriptional activator protein (TrAP) with the homologs encoded by African cassava mosaic virus (ACMV), East African cassava mosaic virus (EACMV), Indian cassava mosaic virus (ICMV), Tomato yellow leaf curl China virus (TYLCCNV), and Tomato golden mosaic virus (TGMV). The previously identified basic (box a), cys-his (box b), and acidic (box c) domains are indicated. The minimal sequence important for transactivation of the virion-sense promoters of TGMV are shown in bold. Amino acid sequences of ToLCNDV TrAP important in the inhibition of programmed cell death are shown underlined. The conserved amino acid sequences of the zinc finger motif (C-X-C-X7-C-X6-H-X4-HC) are highlighted within box b. 
these hosts by ToLCNDV is not associated with an HR response, leading us to hypothesize that the virus encodes a factor (or factors) that abrogate the HR-induced cell death. This hypothesis was confirmed using transient assays in which NSP was coexpressed with infectious (when coinoculated) clones of ToLCNDV DNA A or DNA B. This established that some factor encoded by the DNA A component was capable of preventing NSP-induced HR. Further assays, in which each of the DNA A-encoded genes was coexpressed with NSP, demonstrated that the anti-HR phenomenon is mediated by TrAP.

The TrAP of begomoviruses is multifunctional. It is a transcription factor required for the expression of late viral genes (Sunter and Bisaro 1991), can be a pathogenicity factor (van Wezel et al. 2001) and a suppressor of PTGS (van Wezel et al. 2002 b), conditions a virus-nonspecific enhanced-susceptibility phenotype in transgenic plants (Sunter et al. 2001), and also interacts with and inactivates SNF1-related kinase (Hao et al. 2003) and adenosine kinase (Wang et al. 2003). Some of the functions of begomovirus-encoded TrAP have been mapped to specific amino acid sequences (Sunter and Bisaro 2003) (Figs. 3 and 4). Our deletion mutagenesis studies indicate that TrAP sequences important in mediating suppression of PTGS, pathogenicity, and DNA binding are also important for mediating inhibition of HR, whereas amino acid sequences involved in transactivation (C-terminal sequences) (Fig. 4, box c) are not. Thus, the domains important for suppression of PTGS are the same as those involved in suppression of cell death.

TrAP is localized in the nucleus, possessing a functional NLS within a region of basic amino acids (Fig. 4, box a). Consisting of four consecutive arginine residues (which are highly conserved between begomoviruses), the NLS is essential for nuclear localization. TrAP mutants that are defective in nuclear import are unable to induce a necrotic response or mediate suppression of PTGS (Dong et al. 2003). Similarly, mutations in the ZF motif of Tomato yellow leaf curl China virus (TYLCCNV, a monopartite begomovirus) TrAP abolished its ability to suppress PTGS and induce a necrotic response, correlating with a loss of zinc and DNA-binding activity (van Wezel et al. 2002b). These results provide strong circumstantial evidence that these processes, induction of a necrotic response and suppression of PTGS, are mediated in the nucleus and require a functional ZF motif, suggesting that DNA binding is involved.

PTGS is an antiviral defense mechanism of plants and is manifested by homology-dependent RNA degradation (Voinnet 2001). To counter this defense, viruses have evolved counteractive functions by encoding proteins that are capable of suppressing PTGS (Voinnet et al. 1999). A number of such proteins, including cucumovirus $2 \mathrm{~b}$, potyvirus HC-Pro, sobemovirus $\mathrm{P} 1$, and geminivirus TrAP, have been studied (Roth et al. 2004). Plants employ a second form of defense against viruses that works on a classical gene-for-gene basis. In this case, a virusencoded elicitor, the avirulence determinant, is the target of a host-encoded resistance $(R)$ gene which triggers an HR. Examples of $R$ genes include the $R x$ gene from potato against PVX (Bendahmane et al. 1999) and the $N$ gene of tobacco providing resistance against Tobacco mosaic virus (Whitham et al. 1994). Thus, it is possible that ToLCNDV- and TYLCCNVencoded TrAPs interfere with both of these host defense pathways, although for neither system has the presence of a hostencoded resistance gene been demonstrated. At least one other plant virus-encoded product, the $2 \mathrm{~b}$ protein encoded by cucumoviruses, interacts with both pathways. Zucchini yellow mosaic virus-encoded $2 \mathrm{~b}$ is a suppressor of PTGS and an elicitor of PCD (Ryang et al. 2004, 2005). It is not uncommon for animal-infecting viruses to encode factors that function to both promote and inhibit PCD. The effective exploitation of cell death may be a determining factor in virus survival. Many ani- mal viruses, such as the Human immunodeficiency virus (HIV), adenoviruses, and herpes simplex viruses, are reported to encode proteins which mediate both these activities (Benetti et al. 2003; Hay and Kannourakis 2002).

Table 1. Primers used for production of constructs of Tomato leaf curl New Delhi virus genes under the control of the Cauliflower mosaic virus $35 \mathrm{~S}$ promoter ${ }^{\mathrm{a}}$

\begin{tabular}{|c|c|}
\hline Gene construct & Primer sequences \\
\hline Rep/35S & $\begin{array}{l}\text { AC1 F 5'-GGCCATGGATGGCTCCGCCACGACG } \\
\text { TCGTTT-3' } \\
\text { AC1 R 5'-GGGTCGACTCAACTCGCCTCCTGAG } \\
\text { AATGC-3' }\end{array}$ \\
\hline $\operatorname{TrAP} / 35 \mathrm{~S}$ & $\begin{array}{l}\text { AC2 F 5'-CCATGGATGCAGTCTTCATCACACTC } \\
\text { GA-3' } \\
\text { AC2 R 5'-GTCGACTAAGGACCTGGGTTTTGAA } \\
\text { GACT-3' }\end{array}$ \\
\hline $\mathrm{TrAP}^{\mathrm{NT}} / 35 \mathrm{~S}$ & $\begin{array}{l}\text { AC2 F 5'-CCATGGATGCAGTCTTAATCACACTC } \\
\text { GA-3' } \\
\text { AC2 R 5'-GTCGACTAAGGACCTGGGTTTTGAA } \\
\text { GACT-3' }\end{array}$ \\
\hline $\operatorname{TrAP}^{\mathrm{dmN} 20} / 35 \mathrm{~S}$ & $\begin{array}{l}\text { N20 F 5'-ACCATGGATGCAGAAGAAGAAGAAG } \\
\text { AGC-3' } \\
\text { AC2 R 5'-GTCGACTAAGGACCTGGGTTTTGAA } \\
\text { GACT-3' }\end{array}$ \\
\hline $\operatorname{TrAP}^{\mathrm{dmN} 60} / 35 \mathrm{~S}$ & $\begin{array}{l}\text { N60 F 5'-ACCATGGATGTCGAGCAGAGAGTGG } \\
\text { CGT-3' } \\
\text { AC2 R 5'-GTCGACTAAGGACCTGGGTTTTGAA } \\
\text { GACT-3' }\end{array}$ \\
\hline $\operatorname{TrAP}^{\mathrm{dmC} 20} / 35 \mathrm{~S}$ & $\begin{array}{l}\text { C20 F 5'-AGTCGACTAACAGATTTTGAAAGTTA } \\
\text { GA-3' } \\
\text { AC2 F 5'-CCATGGATGCAGTCTTCATCACACTC } \\
\text { GA-3' }\end{array}$ \\
\hline $\operatorname{TrAP}^{\mathrm{dmC} 40} / 35 \mathrm{~S}$ & $\begin{array}{l}\text { C40 F 5'-AGTCGACTAATCATCAAGATTCAAAT } \\
\text { ACA-3' } \\
\text { AC2 F 5'-CCATGGATGCAGTCTTCATCACACTC } \\
\text { GA-3' }\end{array}$ \\
\hline $\operatorname{TrAP}{ }^{\mathrm{dm} 60-80} / 35 \mathrm{~S}$ & $\begin{array}{l}\text { MDM R 5'-AGAATTCCGCAGTGATGTACTCCC } \\
\text { CT-3' } \\
\text { MDM F 5'-AGAATTCGAAGCACGACAGCAGG } \\
\text { CC-3' }\end{array}$ \\
\hline $\operatorname{TrAP}^{\mathrm{dmNLS}} / 35 \mathrm{~S}$ & $\begin{array}{l}\text { AC2N15R 5'-GGAATTCCGCACCGGAATAGAGT } \\
\text { GG-3' } \\
\text { AC2N31F 5'-GGAATTCCGTTGATCTCCCGTGT } \\
\text { GGGTG-3' }\end{array}$ \\
\hline $\mathrm{TrAP}^{\mathrm{dmZF}} / 35 \mathrm{~S}$ & $\begin{array}{l}\text { AC2N35R 5'-GGAATTCCCGGGAGATCAACTCG } \\
\text { CCTCC-3' } \\
\text { AC2N61F 5'-GGAATTCCTCGAGCAGAGAGTGG } \\
\text { CTTAT-3' }\end{array}$ \\
\hline $\mathrm{REn} / 35 \mathrm{~S}$ & $\begin{array}{l}\text { AC3 F 5'-GGCCATGGATGATTACGGATTCACT } \\
\text { CAC-3' } \\
\text { AC3 R 5'-GGGTCGACTAATAAATATCAAGCTT } \\
\text { TAT-3' }\end{array}$ \\
\hline $\mathrm{AC} 4 / 35 \mathrm{~S}$ & $\begin{array}{l}\text { AC4 F 5'-ACCATGGATGGGTCTCCGCATATCC } \\
\text { ATG-3' } \\
\text { AC4 R 5'-AGTCGACTAGAACGTCTCCGTCTTT } \\
\text { GTC-3' }\end{array}$ \\
\hline AC $5 / 35 \mathrm{~S}$ & $\begin{array}{l}\text { AC5 F 5'-GGCCATGGATGCATGTTCTTCACCGT } \\
\text { TG-3' } \\
\text { AC5 R 5'-GGGTCGACTCAACGCCCGCATCGAA } \\
\text { GGT-3' }\end{array}$ \\
\hline $\mathrm{CP} / 35 \mathrm{~S}$ & $\begin{array}{l}\text { AV1 F 5'-ACCATGGATGGCGAAGCGACCAGCA } \\
\text { GAT-3' } \\
\text { AV1 R 5'-GGTCGACTTAATTTGTTACCGAATC } \\
\text { ATA-3' }\end{array}$ \\
\hline $\mathrm{AV} 2 / 35 \mathrm{~S}$ & $\begin{array}{l}\text { AV2 F 5'-GCCATGGATGTGGGATCCATTGTTG } \\
\text { GAC-3' } \\
\text { AV2 R 5'-GGTCGACCTATACATTCTGTACATT } \\
\text { CTG-3' }\end{array}$ \\
\hline $\mathrm{GFP}^{\mathrm{RNAi}} / 35 \mathrm{~S}$ & $\begin{array}{l}\text { GFP F 5'-ATAAGGATCCGTAAAGGGAAGAAC } \\
\text { TT-3' } \\
\text { GFP R 5'-TCTAGATGATTTGTATAGTTCATCC } \\
\text { AT-3' }\end{array}$ \\
\hline
\end{tabular}

${ }^{\text {a }}$ Primers used for construction of RNAi construct for silencing of green fluorescent protein also are given. 
Coinoculation of NSP with intact clones of the genomes (or DNA A genomic components) of three distinct begomovirus species showed only one, ICMV, to inhibit the HR. The reason for this is unclear but may indicate that putative factors mediating anti-HR for ACMV and CLCuMV are encoded on other components (DNA B or DNA $\beta$ [an essential satellite component associated with some begomoviruses] [Mansoor et al. 2003a], respectively) or interfere with alternative pathways leading to HR that are not activated by ToLCNDV NSP. Begomoviruses differ in their adaptation to circumvent PTGS. The TrAP encoded by ACMV is only a weak suppressor of PTGS whereas the AC4 protein is a strong suppressor, as well as binding and inactivating microRNA (Chellappan et al. 2005). In contrast, for various begomoviruses, including the related East African cassava mosaic virus, TrAP has been shown to mediate strong suppression of PTGS (Chellappan et al. 2005; van Wezel et al. 2002b). We have shown the TrAP of ToLCNDV to have suppressor activity. This illustrates that viruses, even within the same genus, have evolved different mechanisms to overcome host defenses including, most likely, the ability to inhibit the HR.

Our results show that phytopathogenic viruses, like their animal-infecting counterparts, have adapted to counter celldeath-mediated host defenses. These findings will help in understanding how plant viruses are capable of overcoming defense responses mediated by gene silencing and $R$ gene pathways and how these two arms of the defense system of plants interact. Efforts are now underway to identify TrAP interactors which potentially are involved in initiating the host-encoded HR response. We also are trying to determine whether the ability of TrAP to overcome HR is a direct effect or is indirectly mediated, possibly by inhibiting microRNAs involved in cell death. A further important question is whether the ability to overcome cell death is a feature of only plant DNA viruses that replicate in the nucleus or if it is a general response employed by all phytopathogenic viruses.

\section{MATERIALS AND METHODS}

\section{Gene constructs.}

Constructs used in this study were derived from the infectious cloned components of ToLCNDV (Padidam et al. 1995). The constructs for the expression of the ToLCNDV genes encoding MP and NSP, encoded on DNA B, in the binary vector pBinPlus have been described previously (Hussain et al. 2005). Similar constructs for the expression of all ToLCNDV DNA A-encoded genes were produced by polymerase chain reaction-mediated amplification of the coding sequences using specific oligonucleotide primers (Table 1). Restriction endonuclease recognition sites for $\mathrm{NcoI}$ and SalI were included in the forward and reverse primers, respectively, to allow directional cloning in the expression vector pJIT 163 (Guerineau et al. 1992). All gene constructs were end sequenced to confirm their integrity.

Resulting pJIT163 expression cassettes were transferred into the binary vector pGreen0029 (Hellens et al. 2000) as KpnIEcoRV fragments. The pGreen expression constructs finally were transformed into Agrobacterium tumefaciens GV1301 by electroporation. Agrobacterium cultures for inoculation were grown at $28^{\circ} \mathrm{C}$ for $48 \mathrm{~h}$ to an optical density at $600 \mathrm{~nm}$ of 0.6 . The bacterial cultures were pelleted $(5,000 \times g$ for $15 \mathrm{~min}$ at $20^{\circ} \mathrm{C}$ ), resuspended in $10 \mathrm{mM} \mathrm{MgCl}_{2}$ containing acetosyringone at $150 \mathrm{mg} / \mathrm{ml}$, and incubated for a minimum of $3 \mathrm{~h}$ at room temperature before use. A further construct for PTGS of GFP expression in $N$. benthamiana line $16 \mathrm{C}$ was produced by cloning a fragment of the GFP gene in both sense and antisense orientations in the double-stranded RNA binary vector
pFGC5941 and was named GFPRNAi/35S. The oligonucleotide primers used for the amplification of GFP sequences are given in Table 1.

\section{Production of $\operatorname{TrAP}$ deletion mutants.}

Deletion mutants of TrAP were produced by designing oligonucleotides to delete 20 and $60 \mathrm{~N}$-terminal amino acids, yielding mutants $\operatorname{TrAP}^{\mathrm{dmN} 20} / 35 \mathrm{~S}$ and $\mathrm{TrAP}^{\mathrm{dmN} 60} / 35 \mathrm{~S}$, respectively. A methionine initiation codon was introduced in the oligonucleotides for these N-terminal mutations (Table 1). Similarly, 20 and 40 amino acids were deleted from the C-terminus by inclusion of a premature stop codon introduced in the oligonucleotides, yielding mutants $\operatorname{TrAP}^{\mathrm{dmC} 20} / 35 \mathrm{~S}$ and $\operatorname{TrAP} \mathrm{dmC}^{\mathrm{dm}} /$ $35 \mathrm{~S}$, respectively. Another deletion mutant of TrAP was produced by deletion of 20 amino acids in the central region between amino acid coordinates 60 and 80, generating TrAP ${ }^{\mathrm{dm} 60-}$ ${ }^{80} / 35 \mathrm{~S}$. For this construct, two extra primers (Table 1) were designed to amplify two fragments from the N-terminal and $\mathrm{C}$ terminal ends, which then were religated. Two further deletion mutants were produced with deletions of the NLS (amino acids 15 to 31 ) and ZF (amino acids 35 to 61) domains: constructs $\mathrm{TrAP}^{\mathrm{dmNLS}} / 35 \mathrm{~S}$ and $\mathrm{TrAP} \mathrm{P}^{\mathrm{dmZF}} / 35 \mathrm{~S}$ respectively. A nontranslatable gene construct ( $\left.\mathrm{TrAP} \mathrm{NT}^{\mathrm{NT}} / 35 \mathrm{~S}\right)$, having a stop codon in place of the initiation codon was produced as a negative control.

\section{Inhibition of HR assays.}

N. tabacum (cv. Samsun NN) and Lycopersicon esculentum (cv. Nagina or Moneymaker) were grown in a controlled environment chamber at $25^{\circ} \mathrm{C}$ with supplementary lighting to yield a 16-h photoperiod. Assays to investigate the ability of various ToLCNDV gene products to inhibit NSP-induced HR were conducted by mixing Agrobacterium cultures harboring $\mathrm{NSP} / 35 \mathrm{~S}$ in equal volumes with cultures containing the various pGreen constructs. The mixed cultures were infiltrated into fully expanded leaves as described previously (Hussain et al. 2005). In these experiments, dilution factors were carefully optimized, because the NSP construct is able to induce an HR at relatively low optical density (0.2). All plant inoculation assays were repeated a minimum of three times.

\section{Transactivation assays.}

The ability of ToLCNDV TrAP to transactivate the virionsense promoter was assessed using a $\beta$-glucuronidase (GUS) expression assay. A GUS expression cassette was produced from pJIT166 by replacing the $35 \mathrm{~S}$ promoter with an approximately 200-bp fragment containing the virion-sense promoter of ToLCNDV DNA A. The promoter fragment was produced using primers CPproF (5'-GGGAGCTCGAATGGCCGCGCA AATTTTTG-3') and CPproR (5'-GGAAGCTTTTGCTCGGA GAACAAGAATGAG- $3^{\prime}$ ), which included the recognition sites for SacI and HindIII, respectively, for directional cloning in pJIT166. The expression cassette then was transferred as a SacI-XhoI fragment to the binary vector pGreen0029. This was introduced into Agrobacterium spp. and coinoculated to plants, with TrAP expression constructs, as described above.

\section{Inoculation with homologous and heterologous begomoviruses.}

The production of partial repeat constructs of the genomic components of ToLCNDV have been described (Padidam et al. 1995). These were transferred into the binary vector $\mathrm{pBin} 19$ for agroinoculation or agroinfiltration. The production of partial repeats of the genomes (or DNA A genomic components) of CLCuMV, ACMV, and ICMV for Agrobacterium-mediated inoculation have been described (Klinkenberg et al. 1989; Mansoor et al. 2003b; Saunders et al. 2002). These were coinfiltrated to tomato or tobacco leaves with NSP/35S as described above. 


\section{PTGS assays.}

The suppressor of PTGS activity of ToLCNDV TrAP was conducted in $N$. benthamiana line 16c (Ruiz et al. 1998). Equal volumes of A. tumefaciens cultures harboring plasmids $\mathrm{GFP}^{\mathrm{RNAi}} / 35 \mathrm{~S}$ and $\mathrm{TrAP} / 35 \mathrm{~S}$ were mixed and coinfiltrated into the underside of leaves using a 5-ml syringe. A clone of $35 \mathrm{SP} 19$ was kindly provided by D. Baulcombe and was used as positive control in suppression of PTGS analysis. GFP fluorescence was observed using a 100-W, long-wave UV lamp (UltraLum, Inc., Paramount, CA, U.S.A.). Photographs were taken under long-wave UV illumination using a Black Ray lamp (UV Products, Upland, CA, U.S.A.).

\section{ACKNOWLEDGMENTS}

This work was funded by grants from the International Center for $\mathrm{Ge}-$ netic Engineering and Biotechnology (ICGEB) to S. Mansoor and a grant from the Ministry of Science and Technology (MoST), Government of Pakistan. R. W. Briddon is supported by Higher Education Commission (HEC) of the Government of Pakistan under the "Foreign Faculty Hiring Scheme." We thank C. M. Fauquet for providing the clones of ToLCNDV, P. M. Mullineaux for providing pJIT163/pJIT166, and J. Stanley for providing clones of ACMV and ICMV. We also thank D. Baulcombe for providing the P19 clone and R. Jorgenson for providing pFGC5901.

\section{LITERATURE CITED}

Baker, B., Zambryski, P., Staskawicz, B., and Dinesh-Kumar, S. P. 1997. Signaling in plant-microbe interactions. Science 276:726-733.

Balague, C., Lin, B., Alcon, C., Flottes, G., Malmstrom, S., Kohler, C., Neuhaus, G., Pelletier, G., Gaymard, F., and Roby, D. 2003. HLM1, an essential signaling component in the hypersensitive response, is a member of the cyclic nucleotide-gated channel ion channel family. Plant Cell $15: 365-379$.

Bendahmane, A., Kanyuka, K., and Baulcombe, D. C. 1999. The Rx gene from potato controls separate virus resistance and cell death responses. Plant Cell 11:781-791.

Benetti, L., Munger, J., and Roizman, B. 2003. The herpes simplex virus 1 US3 protein kinase blocks caspase-dependent double cleavage and activation of the proapoptotic protein BAD. J. Virol. 77:6567-6573.

Briddon, R. W., and Stanley, J. 2006. Sub-viral agents associated with plant-infecting single-stranded DNA viruses. Virology 344:198-210.

Chellappan, P., Vanitharani, R., and Fauquet, C. M. 2005. MicroRNAbinding viral protein interferes with Arabidopsis development. Proc. Natl. Acad. Sci. U.S.A. 102:10381-10386.

Clough, S. J., Fengler, K. A., Yu, I. C., Lippok, B., Smith, R. K., Jr., and Bent, A. F. 2000. The Arabidopsis dnd1 "defense, no death" gene encodes a mutated cyclic nucleotide-gated ion channel. Proc. Natl. Acad. Sci. U.S.A. 97:9323-9328.

Dangl, J. L., Dietrich, R. A., and Richberg, M. H. 1996. Death don't have no mercy: Cell death programs in plant-microbe interactions. Plant Cell 8:1793-1807.

Dong, X., van Wezel, R., Stanley, J., and Hong, Y. 2003. Functional characterization of the nuclear localization signal for a suppressor of posttranscriptional gene silencing. J. Virol. 77:7026-7033.

Garrido-Ramirez, E. R., Sudarshana, M. R., Lucas, W. J., and Gilbertson, R. L. 2000. Bean dwarf mosaic virus BV1 protein is a determinant of the hypersensitive response and avirulence in Phaseolus vulgaris. Mol. Plant-Microbe Interact. 13:1184-1194.

Greenberg, J. T., and Yao, N. 2004. The role and regulation of programmed cell death in plant-pathogen interactions. Cell. Microbiol. 6:201-211.

Guerineau, F., Lucy, A., and Mullineaux, P. 1992. Effect of two consensus sequences preceding the translation initiator codon on gene expression in plant protoplasts. Plant Mol. Biol. 18:815-818.

Hammond-Kosack, K. E., and Jones, J. D. G. 1996. Resistance gene dependent plant defense responses. Plant Cell 8:1773-1791.

Hanley-Bowdoin, I., Settlage, S. B., and Robertson, D. 2004. Reprogramming plant gene expression: A prerequisite to geminivirus DNA replication. Mol. Plant Pathol. 5:149-156.

Hao, L., Wang, H., Sunter, G., and Bisaro, D. M. 2003. Geminivirus AL2 and L2 proteins interact with and inactivate SNF1 kinase. Plant Cell 15:1034-1048.

Hay, S., and Kannourakis, G. 2002. A time to kill: Viral manipulation of the cell death program. J. Gen. Virol. 83:1547-1564.

Heath, M. C. 2000. Hypersensitive response-related death. Plant Mol. Biol. 44:321-334.
Hellens, R. P., Edwards, E. A., Leyland, N. R., Bean, S., and Mullineaux, P. M. 2000. pGreen: A versatile and flexible binary Ti vector for Agrobacterium-mediated plant transformation. Plant Mol. Biol. 42:819-832.

Hoeberichts, F. A., and Woltering, E. J. 2002. Multiple mediators of plant programmed cell death: Interplay of conserved cell death mechanisms and plant-specific regulators. BioEssays 25:47-57.

Hussain, M., Mansoor, S., Iram, S., Fatima, A. N., and Zafar, Y. 2005. The nuclear shuttle protein of Tomato leaf curl New Delhi virus is a pathogenicity determinant. J. Virol. 79:4434-4439.

Jurkowski, G. I., Smith, J., R. K., Yu, I., Ham, J. H., Sharma, S. B., Klessig, D. F., Fengler, K. A., and Bent, A. F. 2004. Arabidopsis DND2, a second cyclic nucleotide-gated ion channel gene for which mutation causes the "defense, no death" phenotype. Mol. Plant-Microbe Interact. 17:511-520.

Klinkenberg, A., Ellwood, S., and Stanley, J. 1989. Fate of African cassava mosaic virus coat protein deletion mutants after agroinoculation. J. Gen. Virol. 70:1837-1844.

Loake, G. 2001. Plant cell death: Unmasking the gatekeepers. Curr. Biol. 11:R1028-R1031.

Mansoor, S., Briddon, R. W., Zafar, Y., and Stanley, J. 2003a. Geminivirus disease complexes: An emerging threat. Trends Plant Sci. 8:128-134.

Mansoor, S., Briddon, R. W., Bull, S. E., Bedford, I. D., Bashir, A., Hussain, M., Saeed, Zafar, M. Y., Malik, K. A., Fauquet, C., and Markham, P. G. 2003b. Cotton leaf curl disease is associated with multiple monopartite begomoviruses supported by single DNA $\beta$. Arch. Virol. 148:1969-1986.

Morel, J. B., and Dangl, J. L. 1997. The hypersensitive response and the induction of cell death in plants. Cell Death Diff. 4:671-683.

Nozue, M., Tomiyama, K., and Doke, N. 1997. Effect of blasticidin S on development of potential of potato tuber cells to react hypersensitively to infection by Phytophthora infestans. Physiol. Plant Pathol. 10:181-189.

Padidam, M., Beachy, R. N., and Fauquet, C. M. 1995. Tomato leaf curl geminivirus from India has a bipartite genome and coat protein is not essential for infectivity. J. Gen. Virol. 76:25-35.

Raghavan, V., Malik, P. S., Choudhury, N. R., and Mukherjee, S. K. 2004. The DNA-A component of a plant geminivirus (Indian mung bean yellow mosaic virus) replicates in budding yeast cells. J. Virol. 78:24052413.

Rojas, M. R., Hagen, C., Lucas, W. J., and Gilbertson, R. L. 2005. Exploiting chinks in the plant's armor: Evolution and emergence of geminiviruses. Annu. Rev. Phytopathol. 43:361-394.

Roth, B. M., Pruss, G. J., and Vance, V. B. 2004. Plant viral suppressors of RNA silencing. Virus Res. 102:97-108.

Ruiz, T. M., Voinnet, O., and Baulcombe, D. C. 1998. Initiation and maintenance of virus-induced gene silencing. Plant J. 10:937-946.

Ryang, B.-S., Kobori, T., Matsumoto, T., Kosaka, Y., and Ohki, S. T. 2004. Cucumber mosaic virus $2 \mathrm{~b}$ protein compensates for restricted systemic spread of Potato virus $Y$ in doubly infected tobacco. J. Gen. Virol. 85 (11):3405-3414.

Ryang, B.-S., Matsumoto, T., Kobori, T., Kosaka, Y., and Ohki, S. T. 2005. $2 \mathrm{~b}$ Protein is essential to induce a novel gradual cell death in Zucchini yellow mosaic virus-inoculated cucumber cotyledon co-infected with Cucumber mosaic virus. J. Gen. Plant Pathol. 71:308-313.

Sanderfoot, A. A., and Lazarowitz, S. G. 1996. Getting it together in plant virus movement: Cooperative interactions between bipartite geminivirus movement proteins. Trends Cell Biol. 6:353-358.

Saunders, K., Salim, N., Mali, V. R., Malathi, V. G., Briddon, R. W., Markham, P. G., and Stanley, J. 2002. Characterisation of Sri Lankan cassava mosaic virus and Indian cassava mosaic virus: Evidence for acquisition of a DNA B component by a monopartite begomovirus. Virology 293:63-74.

Selth, L. A., Randles, J. W., and Rezaian, M. A. 2004. Host responses to transient expression of individual genes encoded by Tomato leaf curl virus. Mol. Plant-Microbe Interact. 17:27-33.

Stanley, J., Bisaro, D. M., Briddon, R. W., Brown, J. K., Fauquet, C. M., Harrison, B. D., Rybicki, E. P., and Stenger, D. C. 2005. Geminiviridae. In: Virus Taxonomy, VIIIth Report of the ICTV. C. M. Fauquet, M. A. Mayo, J. Maniloff, U. Desselberger, and L. A. Ball, eds. Elsevier/Academic Press, London.

Sunter, G., and Bisaro, D. M. 1991. Transactivation in a geminivirus: AL2 gene product is needed for coat protein expression. Virology 180:416419.

Sunter, G., and Bisaro, D. M. 2003. Identification of a minimal sequence required for activation of the Tomato golden mosaic virus coat protein promoter in protoplasts. Virology 305:452-462.

Sunter, G., Sunter, J. L., and Bisaro, D. M. 2001. Plants expressing tomato golden mosaic virus AL2 or beet curly top virus L2 transgenes show enhanced susceptibility to infection by DNA and RNA viruses. Virology 285:59-70.

Trinks, D., Rajeswaran, R., Shivaprasad, P. V., Akbergenov, R., Oakeley, E. J., Veluthambi, K., Hohn, T., and Pooggin, M. M. 2005. Suppression 
of RNA silencing by a geminivirus nuclear protein, AC2, correlates with transactivation of host genes. J. Virol. 79:2517-2527.

Vanitharani, R., Chellappan, P., and Fauquet, C. M. 2003. Short interfering RNA-mediated interference of gene expression and viral DNA accumulation in cultured plant cells. Proc. Natl. Acad. Sci. U.S.A. 100:96329636.

van Wezel, R., Liu, H., Tien, P., Stanly, J., and Hong, Y. 2001. Gene C2 of the monopartite geminivirus Tomato yellow leaf curl virus-China encodes a pathogenicity determinant that is localized in the nucleus. Mol. PlantMicrobe Interact. 14:1125-1128.

van Wezel, R., Dong, X., Blake, P., Stanley, J., and Hong, Y. 2002a. Differential roles of geminivirus Rep and AC4 (C4) in the induction of necrosis in Nicotiana benthamiana. Mol. Plant Pathol. 3:461-471.

van Wezel, R., Dong, X., Liu, H., Tien, P., Stanly, J., and Hong, Y. 2002b. Mutation of three cysteine residues in Tomato yellow leaf curl virus-China C2 protein causes dysfunction in pathogenesis and posttranscriptional gene silencing suppression. Mol. Plant-Microbe Interact. 15:203-208.
Voinnet, O. 2001. RNA silencing as a plant immune system against viruses. Trends Genet. 17:449-459.

Voinnet, O., Pinto, Y. M., and Baulcombe, D. C. 1999. Suppression of gene silencing: A general strategy used by diverse DNA and RNA viruses of plants. Proc. Natl. Acad. Sci. U.S.A. 23:14147-14152.

Wang, H., Hao, L., Shung, C.-Y., Sunter, G., and Bisaro, D. M. 2003. Adenosine kinase is inactivated by geminivirus AL2 and L2 proteins. Plant Cell 15:3020-3032.

Wang, H., Buckley, K. J., Yang, X., Buchmann, R. C., and Bisaro, D. M. 2005. Adenosine kinase inhibition and suppression of RNA silencing by geminivirus AL2 and L2 proteins. J. Virol. 79:7410-7418.

Whitham, S., Dinesh-Kumar, S. P., Choi, D., Hehl, R., Corr, C., and Baker, B. 1994. The product of the tobacco mosaic virus resistance gene $N$ : Similarity to toll and the interleukin-1 receptor. Cell 78:1101-1115.

Yu, I. C., Parker, J., and Bent, A. F. 1998. Gene-for-gene disease resistance without the hypersensitive response in Arabidopsis dnd1 mutant. Proc. Natl. Acad. Sci. U.S.A. 95:7819-7824. 